ARTICLE

DOI: $10.1038 / \mathrm{s} 41467-018-03532-1$

\title{
Difluoromethylation of (hetero)aryl chlorides with chlorodifluoromethane catalyzed by nickel
}

\author{
Chang Xu', Wen-Hao Guo ${ }^{1}$, Xu He${ }^{1}$, Yin-Long Guo ${ }^{1}$, Xue-Ying Zhang ${ }^{1}$ \& Xingang Zhang (i) ${ }^{1}$
}

Relatively low reactivity hinders using chlorodifluoromethane $\left(\mathrm{ClCF}_{2} \mathrm{H}\right)$ for general difluoromethylation with organic molecules, despite its availability as an inexpensive industrial chemical. To date, transformations of $\mathrm{ClCF}_{2} \mathrm{H}$ are very limited and most of them involve difluorocarbene intermediate. Here, we describe a strategy for difluoromethylation of aromatics through nickel-catalyzed cross-coupling of $\mathrm{ClCF}_{2} \mathrm{H}$ with readily accessible (hetero)aryl chlorides. The reaction proceeds under mild reaction conditions with high efficiency and features synthetic simplicity without preformation of arylmetals and broad substrate scope, including a variety of heteroaromatics and commercially available pharmaceuticals. The reliable practicability and scalability of the current nickel-catalyzed process has also been demonstrated by several 10-g scale reactions without loss of reaction efficiency. Preliminary mechanistic studies reveal that the reaction starts from the oxidative addition of aryl chlorides to $\mathrm{Ni}(\mathrm{O})$ and a difluoromethyl radical is involved in the reaction, providing a route for applications of $\mathrm{ClCF}_{2} \mathrm{H}$ in organic synthesis and related chemistry.

\footnotetext{
${ }^{1}$ Key Laboratory of Organofluorine Chemistry, Center for Excellence in Molecular Synthesis, Shanghai Institute of Organic Chemistry, University of Chinese Academy of Sciences, Chinese Academy of Sciences, 345 Lingling Road, 200032 Shanghai, China. These authors contributed equally: Chang Xu, Wen-Hao Guo. Correspondence and requests for materials should be addressed to X.Z. (email: xgzhang@mail.sioc.ac.cn)
} 
$\mathrm{D}$ ifluoromethylation of organic molecules using chlorodifluoromethane $\left(\mathrm{ClCF}_{2} \mathrm{H}\right)$, an inexpensive industrial raw material used for production of fluorinated polymers ${ }^{1}$, represents a cost-efficient and straightforward route to the synthesis of paramount important fluorinated compounds ${ }^{2-12}$. Its activation and transformation, however, is still of great challenge, due to the strong $\mathrm{C}-\mathrm{Cl}$ bonding in this gaseous compound. Thus far, most transformation paths of $\mathrm{ClCF}_{2} \mathrm{H}$ involve the difluorocarbene intermediate. The difluorocarbene species formed through pyrolysis at high temperature or through dehydrochlorination under strong basic conditions has very limited synthetic applications: the former is only applied to produce tetrafluoroethylene (TFE) and related fluorinated polymers (e.g., Teflon) ${ }^{1}$, and the latter is used to prepare heteroatom-substituted difluoromethylated compounds $s^{13-16}$. Very recently, we have developed a palladium-catalyzed difluoromethylation of arylborons with $\mathrm{ClCF}_{2} \mathrm{H}$, also via a difluorocarbene pathway (Fig. 1a) ${ }^{17}$. This study has also demonstrated that the activation of $\mathrm{ClCF}_{2} \mathrm{H}$ by transition metal can be conducted under mild reaction conditions and thus has wide application potential.

For both the practical application and the fundamental research, replacing the palladium catalyst by a first-row-based transition metal catalyst would pave a new and more costefficient way for applications of $\mathrm{ClCF}_{2} \mathrm{H}$ in organic synthesis and medicinal chemistry. Instead of $\mathrm{ClCF}_{2} \mathrm{H}$ activation, only rare examples of nickel catalyzed difluoroalkylation have been reported for the cross-coupling of difluoroalkyl chloride $\left(\mathrm{ClCF}_{2} \mathrm{CO}_{2} \mathrm{Et}\right)$ with nucleophilic arylboronic acids, in which the $\mathrm{C}-\mathrm{Cl}$ bond is activated by an ester group $\left(\mathrm{CO}_{2} \mathrm{Et}\right)$ adjacent to the difluorocarbon $^{18-20}$. As an inert substrate, the direct cleavage of $\mathrm{C}-\mathrm{Cl}$ bond in $\mathrm{ClCF}_{2} \mathrm{H}$ remains a great challenge. Herein, we report a nickel-catalyzed reductive cross-coupling between $\mathrm{ClCF}_{2} \mathrm{H}$ and aryl chlorides ${ }^{21-27}$, representing an alternative strategy for the fluoroalkylation reactions. The reaction proceeds under mild reaction conditions with high efficiency and enables difluoromethylation of a variety of inexpensive and readily accessible aryl chlorides, including heteroaromatics and commercially available pharmaceuticals. The reaction can also extend to aryl bromides. In contrast to the difluorocarbene intermediate involved in the previous palladium-catalyzed process, the current Ni-catalyzed difluoromethylations undergoes a difluoromethyl radical pathway through the direct cleavage of $\mathrm{C}-\mathrm{Cl}$ bond in $\mathrm{ClCF}_{2} \mathrm{H}$.

\section{Results}

Optimization of the Ni-catalyzed cross-coupling. We began our studies on nickel-catalyzed reductive cross-coupling between $\mathrm{ClCF}_{2} \mathrm{H}$ and aryl chlorides (Fig. 1b). The use of aryl chlorides is because of their cheapness, ready availability, and more importantly, we proposed a direct transformation that can avoid the need for preformed arylmetals, such as arylborons and arylzincs. A suitable nickel catalytic system is the key to realize this synthesis route. To date, however, such a nickel catalyzed reductive cross-coupling between organohalides and fluoroalkylated electrophiles has not been reported and remains a challenge, because of the difficulties in selectively controlling the catalytic cycle to suppress the side reactions, such as the formation of hydrodehalogenated and dimerized fluorinated byproducts. Although important progresses have been achieved in nickel-catalyzed reductive cross-coupling between aryl halides and unactivated alkyl halides ${ }^{28,29}$, specific challenges still exist in similar reactions of inert aryl chlorides without substitution by electron-withdrawing groups ${ }^{30}$, which is subject to the coupling reaction in the current study.

Accordingly, 1-(tert-butyl)-4-chlorobenzene 2a was chosen as the model substrate for this nickel-catalyzed difluoromethylation reaction (Table 1). Without additives, either no reaction or low yields of difluoromethylated arene $\mathbf{3 a}$ were observed in most of the experiments. The addition of $\mathrm{MgCl}_{2}{ }^{31}$ ( 1.5 equiv.) benefited the reaction with $16 \%$ yield of $3 \mathbf{a}$ obtained when the reaction was carried out with $\mathrm{NiCl}_{2}$.DME (10 mol\%, DME, dimethoxyethane), bpy $\mathbf{L 1}$ (10 mol\%, bpy, 2,2'-bipyridine) and $\mathrm{Zn}$ (2.0 equiv.) in DMA (dimethylacetamide) at $80{ }^{\circ} \mathrm{C}$ (entry 1). But other additives, such as $\mathrm{HCl}$, TMSCl (trimethyl chlorosilane), or DIBAL-H (diisobutyl aluminum hydride) showed no reactivities (Supplementary Table 13). Encouraged by this result, a survey of the reaction parameters, such as ligands, nickel sources, and solvents, was conducted. Unfortunately, no significant improvement of the reaction efficiency was observed (entries 2-4 and Supplementary Tables 1-2). Since a more electron-rich nickel center can benefit the oxidative addition to $\mathrm{C}-\mathrm{Cl}$ bond, the combination of two electron rich ligands L4 and DMAP (4-dimethylaminopyridine $)^{32,33}$ provided $\mathbf{3 a}$ in $46 \%$ yield (entry 5 ). Other pyridinebased ligands were also examined, but were inferior to DMAP (entries 6-8). Decreasing the reaction temperature to $60{ }^{\circ} \mathrm{C}$ with $10 \mathrm{~mol} \%$ of $\mathrm{NiCl}_{2}$ could improve the yield of 3 a to $59 \%$ (entry 9). Further optimization of the reaction conditions

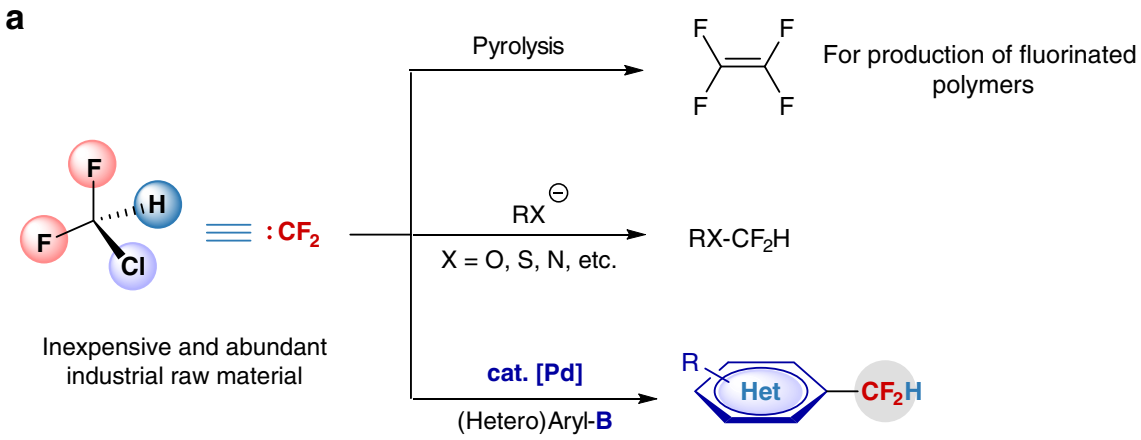

b

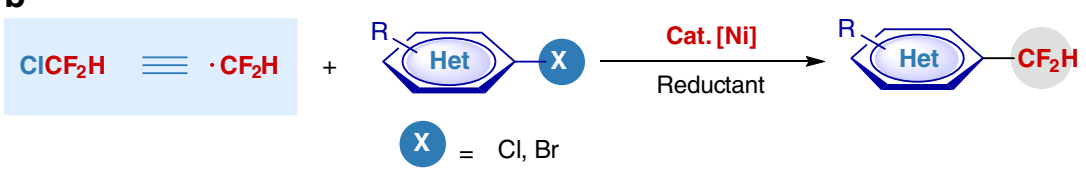

Fig. 1 Strategies in activation of $\mathrm{ClCF}_{2} \mathrm{H}$. a Previous work, activation of $\mathrm{ClCF}_{2} \mathrm{H}$ via a difluorocarbene pathway. $\mathbf{b}$ This work, a new activation of $\mathrm{ClCF}_{2} \mathrm{H}$ through a difluoromethyl radical pathway 
Table 1 Representative results for the optimization of Ni-catalyzed difluoromethylation of $2 \mathrm{a}$ with $\mathrm{C1CF}_{2} \mathrm{H}^{\mathrm{a}}$



(Supplementary Tables $4-12$ ) revealed that the addition of $3 \AA$ molecular sieves (MS) in conjunction with $\mathrm{NiCl}_{2}(15 \mathrm{~mol} \%)$ and L4 (10 mol\%) could afford 3a in 79\% yield (entry 10$)$. In parallel, $\mathrm{NiBr}_{2}$ as an alternative catalyst under the same reaction conditions could also lead to $\mathbf{3 a}$ in a comparable yield (entry 11). It should be mentioned that the use of $10 \mathrm{~mol} \%$ of $\mathrm{NiCl}_{2}$ and 10 mol\% of $\mathbf{L} 4$ with $3 \AA$ MS could also lead to $\mathbf{3 a}$ in a comparable yield (76\%) sometimes. But in most of the cases, we obtained the yields of $3 \mathrm{a}$ in a range of $46 \%$ to $76 \%$. We supposed that the use of excessive $\mathrm{NiCl}_{2}$ vs $\mathbf{L} \mathbf{4}$ was probably because a comproportionation occurred between $\left[\mathrm{Ni}^{\mathrm{II}}\right]$ and in situ generated $\left[\mathrm{Ni}^{0}\right]$. Switching $\mathrm{Zn}$ with organic reductant tetrakis(dimethylamino) ethylene (TDAE) led to no 3a (Supplementary Table 14). The absence of nickel or $\mathbf{L} \mathbf{4}$ failed to provide $\mathbf{3 a}$ either (entries 12 and 13). Thus, these findings demonstrate that $\mathrm{Ni} / \mathbf{L} \mathbf{4}$ and $\mathrm{Zn}$ play an essential role in promotion of the reaction.

Scope of the Ni-catalyzed cross-coupling. With the viable reaction conditions in hand, a variety of aryl chlorides were examined (Table 2). For the electron-neutral aryl chlorides, the use of $10 \mathrm{~mol} \%$ of $\mathrm{NiCl}_{2}$ and $\mathbf{L} \mathbf{4}$ in a low amount as $5 \mathrm{~mol} \%$ still provided corresponding difluoromethylated arenes in high yields $(\mathbf{2} \mathbf{b}-\mathbf{2 d}, \mathbf{2 x}$, and 2y). Although the ortho substituted substrates, such as ortho methyl, fluoride, vinyl and ester substituted phenyl chlorides furnished the difluoromethylated products in lower yields $(2 \mathbf{e}-\mathbf{2 g}$ and $\mathbf{2 n})$, they are still synthetically useful for medicinal chemistry to access otherwise unavailable compounds. Aryl chlorides bearing electrondonating substituents were also amenable to the reaction, leading to $\mathbf{3 h} \mathbf{3} \mathbf{k}$ in moderate to good yields (2h-2k), in which methoxyl group at meta position provided higher yield than that at para position ( $\mathbf{2} \mathbf{i}$ and $\mathbf{2 h}$ ). Thus, the current nickel-catalyzed process shows the much larger substrate scope than the previous nickelcatalyzed reductive cross-coupling, where the electron-rich and -neutral aryl chlorides have no reaction or only lead to poor yields ${ }^{30}$. Electron-deficient aryl chlorides were also competent coupling partners, highlighting the generality of this approach (2l-2r). The reaction exhibited good tolerance to functional groups including base or nucleophile-sensitive moieties, such as alkoxycarbonyl and enolizable ketone, and other groups such as vinyl, methylsulfonyl, nitrile, and substituted piperazine (2g, 2l-2t). Remarkably, alcohol and arylboronate did not interfere with the reaction efficiency, and led to compounds $\mathbf{2 u - 2 w}$ in good yields, featuring the advantages of this approach. Furthermore, the reaction can also extend to aryl bromides, both electron-rich and electron-deficient aryl bromides were suitable substrates $\left(\mathbf{2} \mathbf{c}^{\prime}, \mathbf{2} \mathbf{i}^{\prime}\right.$, and $\left.\mathbf{2} \mathbf{l}^{\prime}\right)$.

Synthesis of fluorinated heteroaromatic compounds is highly relevant to medicinal chemistry. To our delight, heteroaryl chlorides were also amenable to the current nickel-catalyzed reductive cross-coupling (Table 2). Pyridine-, quinoline-, and benzooxazole-containing substrates all underwent the reaction smoothly, leading to corresponding difluoromethylated heteroarenes in moderate to good yields $(\mathbf{4 a - 4 i})$.

We also examined this protocol for direct difluoromethylation of aryl chloride containing pharmaceuticals, since difluoromethyl group is considered as a bioisostere of hydroxyl and thio groups, and also as a lipophilic hydrogen bond donor ${ }^{34,35}$ (Table 3). Commercially available drugs such as fenofibrate, clofibrate, chlorodiphenhydramine and sibutramine underwent the current nickel-catalyzed process smoothly and afforded corresponding difluoromethylated products in good yields $(\mathbf{6 a}-\mathbf{6 d})$. The good tolerance of trialkyl amines of this coupling provides a useful route for the modulation of biologically active molecules. $\mathrm{N}$ Heterocycles containing drugs were also viable in the reaction. 


\section{Table 2 Scope of the nickel-catalyzed reductive cross-coupling of $\mathrm{CICF}_{2} \mathrm{H}$ with aryl chlorides ${ }^{\mathrm{a}}$}

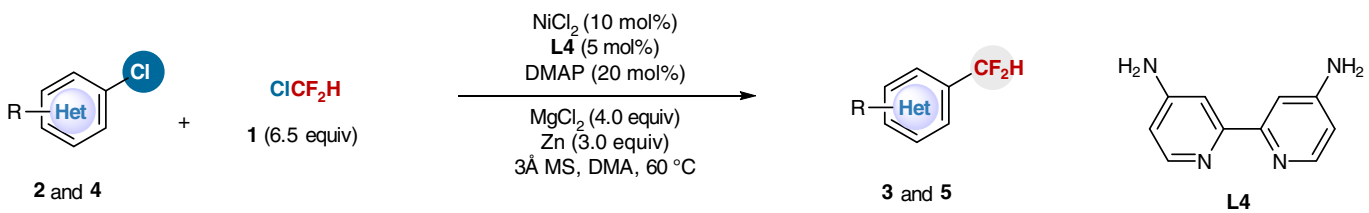<smiles>Clc1ccc(Br)cc1</smiles>

$2 a, 65 \%, 79 \%^{\text {b, c }}, 8 \%^{\text {b, d }}$

2b, $78 \%$ b<smiles>Clc1ccccc1</smiles><smiles>[X]c1ccc(-c2ccccc2)cc1</smiles><smiles>Clc1ccc(Br)cc1</smiles><smiles>O=[N+]([O-])c1ccccc1Cl</smiles><smiles>Fc1ccccc1Cl</smiles><smiles>C=Cc1ccccc1Cl</smiles>

\section{$\mathrm{X}=\mathrm{Cl}, \mathbf{2 c}, 90 \%$
$\mathrm{X}=\mathrm{Br}, 2 \mathbf{c}^{\prime}, 80 \%$}

2d, $75 \%$

2f, $43 \%$ b, c

2g, $49 \%^{\mathrm{c}}$<smiles>[X]c1ccc(OC)cc1</smiles>

$\mathrm{X}=\mathrm{Cl}, p-\mathrm{MeO}, \mathbf{2 h}, 41 \%^{\mathrm{b}, \mathrm{e}}, 7 \%^{\mathrm{b}, \mathrm{d}}$ $X=\mathrm{Cl}, m-\mathrm{MeO}, 2 \mathrm{i}, 70 \%$, c $\mathrm{X}=\mathrm{Br}, m-\mathrm{MeO}, 2 \mathrm{i}, 65 \%$ b, c<smiles>CS(=O)(=O)c1ccc(Cl)cc1</smiles><smiles>CC(=O)Cc1ccc(Cl)cc1</smiles>

$2 r, 50 \%^{c}$ 2s, $80 \%$<smiles>Clc1ccc2ccccc2c1</smiles>

$2 y, 70 \%$<smiles>Clc1cccc2ccccc12</smiles>

$2 x, 68 \%$<smiles>COc1cc(Cl)cc(OC)c1</smiles>

2j, $63 \%$<smiles>Clc1ccc2c(c1)OCO2</smiles>

2k, $55 \%, 60 \%{ }^{\mathrm{b}}$<smiles>[X]c1cccc(C(=O)OCC)c1</smiles>

$\mathrm{X}=\mathrm{Cl}, p-\mathrm{CO}_{2} \mathrm{Et}, 2 \mathrm{2l}, 68 \% \%^{\mathrm{c}}, 50 \%{ }^{\mathrm{d}}$ $\mathrm{X}=\mathrm{Br}, p-\mathrm{CO}_{2} \mathrm{Et}, 2 \mathrm{ll}, 58 \%^{\circ}$ $\mathrm{X}=\mathrm{Cl}, \mathrm{m}-\mathrm{CO}_{2} \mathrm{Et}, 2 \mathrm{~m}, 72 \%^{\mathrm{C}}$ $\mathrm{X}=\mathrm{Cl}, \sigma \cdot \mathrm{CO}_{2} \mathrm{Et}, \mathbf{2 n}, 59 \%^{\mathrm{C}}$<smiles>COc1ccc(Cl)cc1</smiles><smiles>N#CCC(=O)c1ccc(Cl)cc1</smiles>

p-COMe, 2o, $65 \%{ }^{\mathrm{C}}$ $m$-COMe, $2 \mathbf{p}, 72 \%$ 2q, $35 \%{ }^{\circ}$<smiles></smiles>

2t, $86 \%$<smiles>OCc1ccc(Cl)cc1</smiles>

$2 u, 65 \%^{c}, 76 \%^{b, c}$<smiles>OC(c1ccccc1)c1ccc(Cl)cc1</smiles>

2v, $72 \%$<smiles>CC1(C)OB(c2ccc(Cl)cc2)OC1(C)C</smiles>

2w, $60 \%,{ }^{f} 78 \%{ }^{b, t}$<smiles>O=C(c1ccccc1)c1cc(Cl)ccc1Sc1ccccc1</smiles>

$4 a, 60 \%{ }^{\circ}$<smiles>COc1ccc(Cl)cn1</smiles><smiles>[N+]#[N+]c1ccc(Cl)cn1</smiles><smiles>Clc1cccnc1</smiles>

4d, $35 \% \%^{\mathrm{b}, \mathrm{c}}$

$4 b, 58 \%,{ }^{c} 65 \%$, c

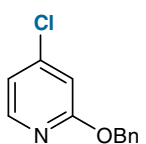

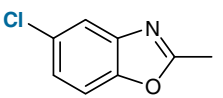

$4 i, 62 \%^{\mathrm{c}}$

a Reaction conditions (unless otherwise specified): (hetero)aryl chloride ( $0.2 \mathrm{mmol}, 1.0$ equiv.), 1 ( $2.6 \mathrm{M}$ in DMA, 6.5 equiv.), DMA ( $2 \mathrm{~mL}$ ), $60^{\circ} \mathrm{C}, 20 \mathrm{~h}$. Average isolated yields from two runs

bYield determined by ${ }^{19} \mathrm{~F}$ NMR using fluorobenzene or trifluorotoluene as an internal standard

c $15 \mathrm{~mol} \%$ of $\mathrm{NiCl}_{2}$ and 10 mol\% of $\mathbf{L 4}$ were used

$\mathrm{d}_{2.0}$ equiv. of $\mathrm{ClCF}_{2} \mathrm{H}$ was used and the reaction was conducted on $3 \mathrm{mmol}$ scale

${ }^{e} 20 \mathrm{~mol} \%$ of $\mathrm{NiBr}_{2}$ and $10 \mathrm{~mol} \%$ of $\mathbf{L 4}$ with or without $3 \AA \mathrm{MS}$ were used

$\mathrm{f}_{2} \mathrm{O} \mathrm{mol} \%$ of $\mathrm{NiCl}_{2}$ and $10 \mathrm{~mol} \%$ of $\mathbf{L} \mathbf{4}$ were used

For instance, clomipramine and buclizine furnished the desired products in good yields (6e and 6f). Although lorcaserin bearing a free amine afforded low yield, the protected $\mathrm{N}$-Boclorcaserin led to difluoromethylated arene efficiently $(\mathbf{6 g})$. Furthermore, $N$-heteroaryl containing drug loratadine was also applicable to the cross-coupling and provided $7 \mathbf{h}$ in $82 \%$ yield (6h). Most importantly, the acetyl protected empagliflozin, a drug used for the treatment of type II diabetes could also provide difluoromethylated product (6i). Although only $25 \%$ yield of $\mathbf{7} \mathbf{i}$ was obtained, this strategy can trade off the yield for fast synthesis of various interesting new biologically active molecules in the late stage without the need for multi-step parallel synthesis. The rebamipide derivative with unprotected amide bond was also a competent coupling partner $(\mathbf{6 j})$. This finding encouraged us to highlight the utility of this protocol further. As shown in $\mathbf{6 k}$, the direct difluoromethylation of protic groups containing drug tolvaptan without protection of hydroxyl and amide bond produced corresponding difluoromethylated product in a yield as high as $92 \%$. Thus, this protocol provides a synthetic simplicity route for the 


\section{Table 3 Late-stage difluoromethylation of pharmaceuticals ${ }^{a}$}

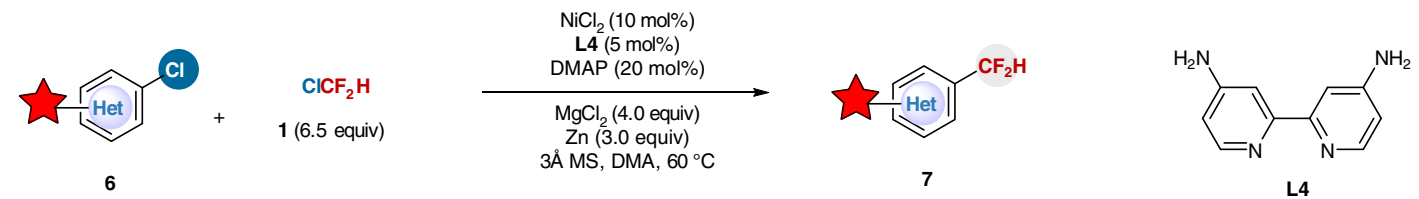<smiles>CCOC(=O)C(C)(C)Oc1ccc(C(=O)c2ccc(Cl)cc2)cc1</smiles>

Fenofibrate

against cardiovascular disease $6 a, 68 \%^{\mathrm{b}}$<smiles>CN(C)CCCN1c2ccccc2CCc2ccc(Cl)cc21</smiles>

Clomipramine antidepressant agent $6 \mathbf{e}, 67 \%$<smiles>CCOC(=O)C(C)(C)Oc1ccc(Cl)cc1</smiles>

Clofibrate

against cardiovascular disease 6b, $72 \%$<smiles>CN(C)CCOC(c1ccccc1)c1ccc(Cl)cc1</smiles>

Chlorodiphenhydramine antihistamine and anticholinergic 6c, $72 \%$<smiles>C[C@@H]1CN(C(=O)OC(C)(C)C)CCc2ccc(Cl)cc21</smiles>

$N($ Boc)-Lorcaserin treatment of obesity $6 \mathrm{~g}, 84 \%^{\mathrm{c}}$<smiles>Cc1ccc(C2(C(CC(C)C)N(C)C)CCC2)cc1</smiles>

Sibutramine ad, $67 \%$<smiles>CCOC(=O)N1CCC(=C2c3ccc(Cl)cc3CCc3cccnc32)CC1</smiles>
Loratadine antihistaminergic agent $6 \mathrm{~h}, 82 \%$<smiles>CC(=O)OC[C@H]1O[C@@H](c2ccc(Cl)c(Cc3ccc(O[C@H]4CCOC4)cc3)c2)[C@H](OC(C)=O)[C@@H](OC(C)=O)[C@@H]1OC(C)=O</smiles>

Protected Empagliflozin treatment of type II diabetes $6 i, 25 \%$, e<smiles>CC(=O)C(Cc1cc(=O)n(C)c2ccccc12)NC(=O)c1ccc(Cl)cc1</smiles>

Rebamipide derivative treatment of gastritis $6 j, 76 \%$<smiles>Cc1ccccc1C(=O)Nc1ccc(C(=O)N2CCC[C@@H](O)c3cc(Cl)ccc32)c(C)c1</smiles>

Tolvaptan treatment of hyponatremia 6 k, $92 \%, 90 \%{ }^{f}$

Reaction conditions (unless otherwise specified): (hetero)aryl chloride ( $0.2 \mathrm{mmol}, 1.0$ equiv.), 1 (2.6 M in DMA, 6.5 equiv.), DMA ( $2 \mathrm{~mL}$ ), $60{ }^{\circ} \mathrm{C}, 20 \mathrm{~h}$. Average isolated yields from two runs

$\mathrm{b}_{2} \mathrm{Omol} \%$ of $\mathrm{NiBr}_{2}$ and $10 \mathrm{~mol} \%$ of $\mathbf{L} \mathbf{4}$ with or without $3 \AA \mathrm{MS}$ were used

${ }_{1} 15 \mathrm{~mol} \%$ of $\mathrm{NiCl}_{2}$ and $10 \mathrm{~mol} \%$ of $\mathbf{L} \mathbf{4}$ were used

dYield determined by ${ }^{19} \mathrm{~F}$ NMR using fluorobenzene as an internal standard

e $20 \mathrm{~mol} \%$ of $\mathrm{NiCl}_{2}$ and $10 \mathrm{~mol} \%$ of $\mathbf{L} \mathbf{4}$ were used

$\mathrm{f}_{2} .0$ equiv. of $\mathrm{ClCF}_{2} \mathrm{H}$ was used and the reaction was conducted on $3 \mathrm{mmol}$ scale

applications in drug discovery and development. Most remarkably, decreasing the loading amount of $\mathrm{ClCF}_{2} \mathrm{H}$ to 2 equiv. still provided difluoromethylated arenes with high efficiency as demonstrated by the synthesis of compounds $\mathbf{2 a}$, $\mathbf{2 h}, \mathbf{2 l}, \mathbf{4 f}$ (Table 2), and $\mathbf{6 k}$ (Table 3), thus demonstrating the advantages of this approach.

To demonstrate the scalability of the current nickel-catalyzed process, several 10-g scale reactions of aryl chlorides were conducted. As shown in Fig. 2a, reaction of $\mathrm{ClCF}_{2} \mathrm{H}$ with $11.3 \mathrm{~g}$ of 4-chloro-1,1'-biphenyl 2c proceeded smoothly under standard reaction conditions, providing $3 \mathrm{c}$ in $80 \%$ yield. The electrondeficient aryl chloride $2 \mathrm{l}$ (11.1g) was also applicable to the reaction and afforded $\mathbf{3 l}$ even in a higher yield (74\%) (Fig. 2b). Notably, substrate bearing a hydroxyl group (2v) could also furnish its corresponding difluoromethylated product $3 \mathbf{v}$ in a much higher yield (90\%) (Fig. 2c). Most remarkably, even 10-g scale late stage difluoromethylation of pharmaceutical tolvaptan 6k, a high yield (91\%) was still obtained (Fig. 2d). It is also worthy to note that decreasing the loading amount of $\mathrm{ClCF}_{2} \mathrm{H}$ to 2 equiv. could also lead to difluoromethylated arene without loss of reaction efficiency as shown by 10 -g scale reaction of $2 \mathbf{v}$ (Fig. 2c), thus demonstrating the good scalability and reliability of this reaction. In light of the wide existence of aryl chloride structural motif in pharmaceuticals and biologically active molecules, this approach would be useful in medicinal chemistry.

\section{Discussion}

In the mechanism study of this reaction, we conducted several experiments. Firstly, to rule out the possible generation of 
a<smiles>Clc1ccc(-c2ccccc2)cc1</smiles>

2c, $11.3 \mathrm{~g}$

( 1.0 equiv) $+\quad \mathrm{CICF}_{2} \mathrm{H}$

(6 equiv)

\section{b}<smiles>CCOC(=O)c1ccc(Cl)cc1</smiles>

2l, $11.1 \mathrm{~g}$

( 1.0 equiv)

(4 equiv)
$+\mathrm{CICF}_{2} \mathrm{H}$<smiles>OC(c1ccccc1)c1ccc(Cl)cc1</smiles>

$2 \mathbf{v}, x \mathrm{~g}$

(1.0 equiv)

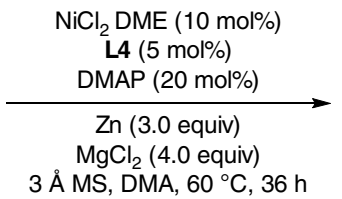

$\mathrm{CF}_{2} \mathrm{H}$

3c, $80 \%, 9.8 \mathrm{~g}$

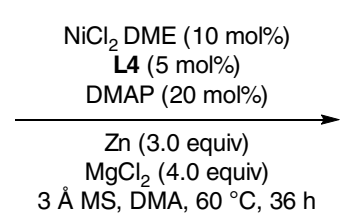<smiles>CCOC(=O)c1ccc(C(F)(F)F)cc1</smiles>

3I, $74 \%, 8.8 \mathrm{~g}$<smiles>OC(c1ccccc1)c1ccc(C(F)(F)F)cc1</smiles>

$x=10.0 \mathrm{~g}, y=6$ equiv, $3 \mathbf{v}, 90 \%, 9.7 \mathrm{~g}$

$x=10.9 \mathrm{~g}, y=2$ equiv, $3 \mathrm{v}, 82 \%, 9.6 \mathrm{~g}$<smiles>Cc1ccccc1C(=O)Nc1ccc(C(=O)N2CCC[C@@H](O)c3cc(Cl)ccc32)c(C)c1</smiles><smiles>[CH]c1cc(NC(=O)c2ccccc2OC)ccc1C(=O)N1CCC[C@@H](O)c2cc(C(F)(F)F)ccc21</smiles>

7k, $91 \%, 10.5 \mathrm{~g}$

(6 equiv)

$\mathrm{Cl}_{2} \mathrm{DME}(10 \mathrm{~mol} \%)$ L4 (5 mol\%) DMAP (20 mol\%)

Zn (3.0 equiv) $\mathrm{MgCl}_{2}$ (4.0 equiv) 3 A MS, DMA, $60{ }^{\circ} \mathrm{C}, 36 \mathrm{~h}$

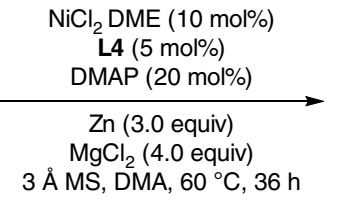

Fig. 2 Ten-gram scale reaction of aryl chlorides with $\mathrm{ClCF}_{2} \mathrm{H}$. a Reaction of $\mathrm{ClCF}_{2} \mathrm{H}$ with $\mathbf{2 c}$. b Reaction of $\mathrm{ClCF}_{2} \mathrm{H}$ with $\mathbf{2 l}$. $\mathbf{c}$ Reaction of $\mathrm{ClCF}_{2} \mathrm{H}$ with $\mathbf{2 v}$. d Reaction of $\mathrm{ClCF}_{2} \mathrm{H}$ with $\mathbf{6 k}$ $\underset{\mathrm{CICF}_{2} \mathrm{H}}{\stackrel{\mathrm{DMA}, 60^{\circ} \mathrm{C}}{\mathrm{Zn}}} \underset{\text { Not observed }}{\left[\mathrm{ClZnCF}_{2} \mathrm{H}\right]+\left|\mathrm{Zn}\left(\mathrm{CF}_{2} \mathrm{H}\right)_{2}\right|}$

b

$\mathrm{CICF}_{2} \mathrm{H}$ reaction conditions $\left.\mid \mathrm{ClZnCF}_{2} \mathrm{H}\right]+\left|\mathrm{Zn}\left(\mathrm{CF}_{2} \mathrm{H}\right)_{2}\right|$

Not observed

C $\left[\mathrm{BrZnCF}_{2} \mathrm{H}\right]$

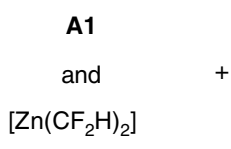

A2<smiles>Clc1ccc(-c2ccccc2)cc1</smiles>

2c

$\mathrm{NiCl}_{2}$ DME (10 mol\%)

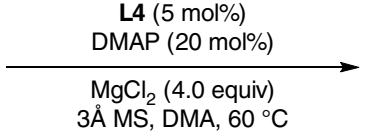

$3 \AA ̊ A M S, D M A, 60^{\circ} \mathrm{C}$<smiles>FC(F)(F)c1ccc(-c2ccccc2)cc1</smiles>

3c, not observed

Fig. 3 Reaction of $\mathrm{ClCF}_{2} \mathrm{H}$ with zinc. a Reaction of $\mathrm{ClCF}_{2} \mathrm{H}$ with zinc in $\mathrm{DMA}$. b Reaction of $\mathrm{ClCF}_{2} \mathrm{H}$ with zinc under standard reaction conditions. $\mathbf{c}$ Reaction of arylchloride $\mathbf{2 c}$ with difluoromethyl zinc species

difluoromethyl zinc species ${ }^{10,11}$ in situ between $\mathrm{ClCF}_{2} \mathrm{H}$ and $\mathrm{Zn}$, we performed control experiments. No difluoromethyl zinc species were observed in the reaction of $\mathrm{ClCF}_{2} \mathrm{H}$ with $\mathrm{Zn}$ in DMA at $60{ }^{\circ} \mathrm{C}$, or even treatment of $\mathrm{ClCF}_{2} \mathrm{H}$ under standard reaction conditions in the absence of aryl chlorides (Fig. 3a, b). Instead, only starting material $\mathrm{ClCF}_{2} \mathrm{H}$ was observed after the reaction. We also prepared difluoromethyl zinc species (A1 and
A2) by reaction of $\mathrm{BrCF}_{2} \mathrm{H}$ with $\mathrm{Zn}$ in DMA at $60^{\circ} \mathrm{C}$ (Supplementary Methods) ${ }^{36}$; however, no desired product $3 \mathrm{c}$ was obtained when these difluoromethyl zinc species were treated with aryl chloride 2c under standard reaction conditions (Fig. 3c). Thus, these results exclude the pathway that the formation of difluoromethylated arenes is derived from the cross-coupling between difluoromethyl zinc species and aryl 
a



b



$2 a$

C
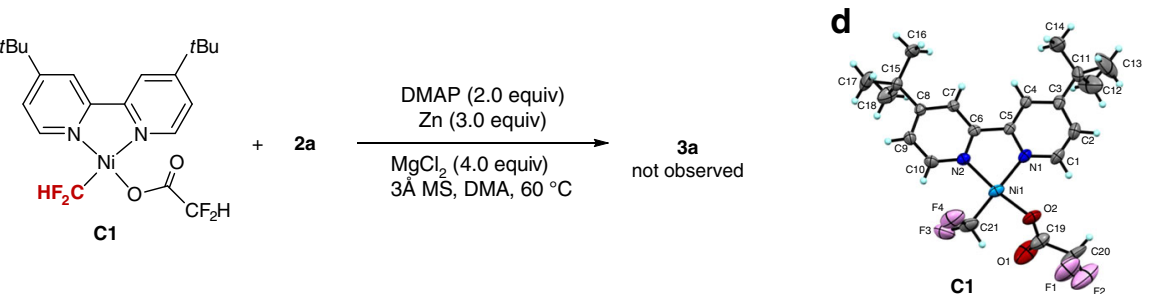

e
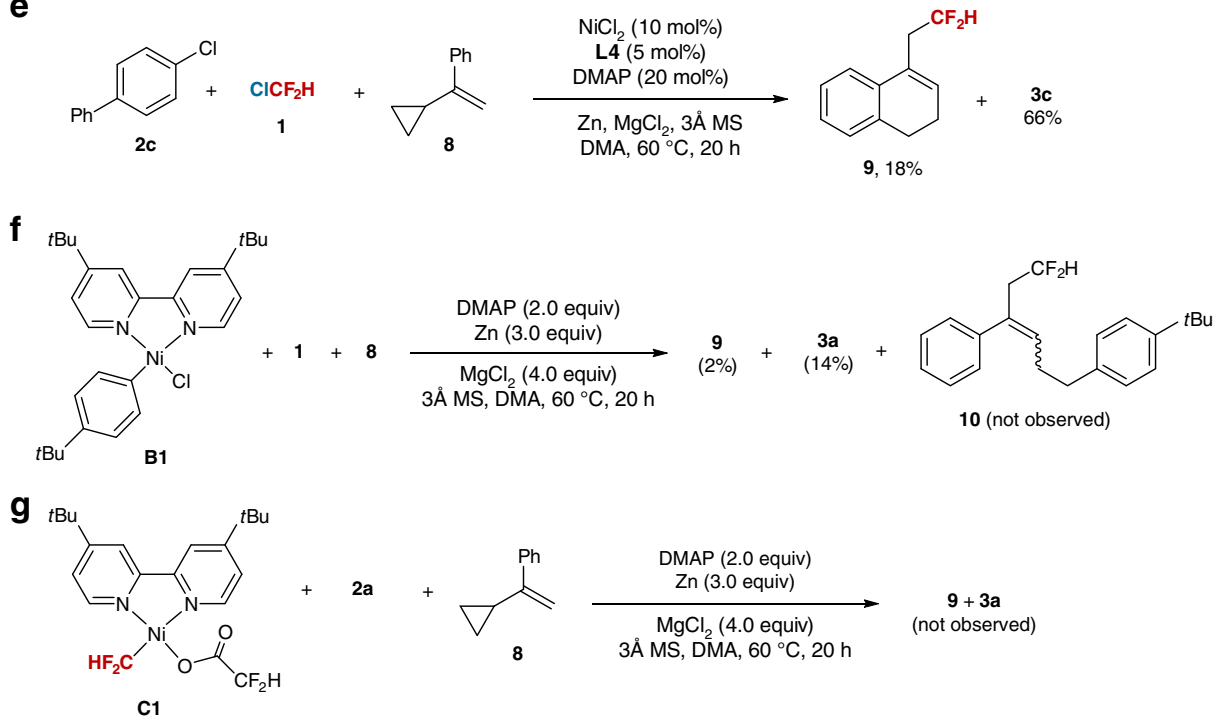

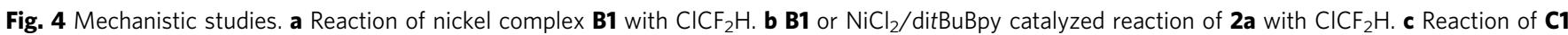
with 2a. $\mathbf{d}$ X-ray crystal structure of $\mathbf{C 1}$. e Experiments to trap the difluoromethyl radical by reaction of $\mathbf{2} \mathbf{c}$ and $\mathbf{8}$ with $\mathrm{CICF}_{2} \mathrm{H}$. $\mathbf{f}$ Reaction of $\mathbf{B} \mathbf{1}$ and $\mathbf{8}$ with $\mathrm{ClCF}_{2} \mathrm{H}$. $\mathbf{g}$ Reaction of $\mathbf{2 a}$ and $\mathbf{8}$ with $\mathbf{C 1}$

chlorides. On the basis of the previous reports ${ }^{28,29}$, we suggest that a nickel-based, reductive cross-coupling catalytic cycle is involved in the reaction.

Secondly, to identify the initiation of current reaction from aryl chloride or $\mathrm{ClCF}_{2} \mathrm{H}$, we prepared aryl nickel complex [ $p$ $t \mathrm{Bu}-\mathrm{PhNi}(\operatorname{dit} \mathrm{BuBpy}) \mathrm{Cl}] \quad(\mathrm{B} \mathbf{1})^{37}$ and difluoromethyl nickel complex $\left[\mathrm{HCF}_{2} \mathrm{Ni}(\mathrm{di} t \mathrm{BuBpy}) \mathrm{HCF}_{2} \mathrm{CO}_{2}\right](\mathbf{C 1})^{38,39}$. The structure of $\mathbf{C l}$ was confirmed by $\mathrm{X}$-ray crystallographic analysis (Fig. 4d). To the best of our knowledge, the preparation of difluoromethyl nickel(II) complex has not been reported so far. The use of $4,4^{\prime}$-ditBu-Bpy (L2) instead of $4,4^{\prime}-\mathrm{diNH}_{2}$-Bpy (L4) is because of the difficulties in isolation of $[\mathrm{Ar}-\mathrm{Ni}(\mathbf{L 4})-\mathrm{Cl}]$ and $\left[\mathrm{CF}_{2} \mathrm{H}-\mathrm{Ni}(\mathbf{L} 4)-\mathrm{HCF}_{2} \mathrm{CO}_{2}\right]$. In addition, $\mathbf{L} 2$ could also promote the reaction under standard reaction conditions and provided 3a in 39\% yield (Fig. 4b). A 15\% yield of 3a was provided when B1 was treated with $\mathrm{ClCF}_{2} \mathrm{H}$ under standard reaction conditions (Fig. 4a). Complex B1 could also serve as a precatalyst and provided $3 \mathbf{a}$ in $43 \%$ yield, which is comparable with the yield obtained by using $\mathrm{NiCl}_{2} /$ ditBuBpy catalytic system (Fig. $4 \mathrm{~b}$ ). However, no $\mathbf{3 a}$ was obtained by reaction of difluoromethyl nickel complex C1 with aryl chloride 2a (Fig. 4c), demonstrating that the current reaction is initiated from aryl chloride and the possibility that the reaction starts from the oxidative addition of $\mathrm{ClCF}_{2} \mathrm{H}$ to $\mathrm{Ni}(0)$ is unlikely.

We also performed control experiments to gain some mechanistic insights into the reaction further (Fig. 4a). The omission of $\mathrm{Zn}$ led to $\mathbf{3 a}$ in only $4 \%$ yield, implying that an active, low-valent nickel species is needed to promote the catalytic cycle by reduction of $\mathrm{Ar}-\mathrm{Ni}^{\mathrm{II}}$ (B1) with $\mathrm{Zn}$. Inspired by the previous report, in which a reduction of $\mathrm{Ar}-\mathrm{Ni}^{\mathrm{II}}$ to $\mathrm{Ar}-\mathrm{Ni}^{\mathrm{I}}$ by reducing metals was proposed in the nickel-catalyzed coupling of aryl chlorides ${ }^{40}$, we envisioned that similar pathway may be involved in the reaction. Furthermore, a lower yield (11\%) of $\mathbf{3 a}$ was provided without $\mathrm{MgCl}_{2}$ (Fig. 4a), indicating that the presence of $\mathrm{MgCl}_{2}$ in current nickel-catalyzed process is probably to facilitate the reduction of nickel(II) complex by $\mathrm{Zn}$ to generate active 
a<smiles>Clc1ccc(Br)cc1</smiles>

$2 a$

b<smiles>Clc1ccc(Br)cc1</smiles>

$2 a$

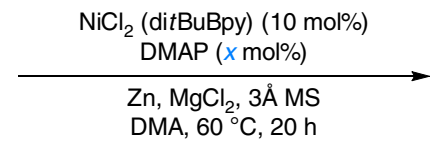

DMA, $60^{\circ} \mathrm{C}, 20 \mathrm{~h}$<smiles>CC(C)c1ccc(Br)cc1</smiles>

$x=20 ; 3 \mathbf{a}, 37 \%$

$x=0 ; \mathbf{3 a}, 16 \%$<smiles>CC(C)(C)c1ccc(C(F)F)cc1</smiles>

$y=10,3 \mathbf{a}, 30 \%$ $y=0,3 a, 0 \%$

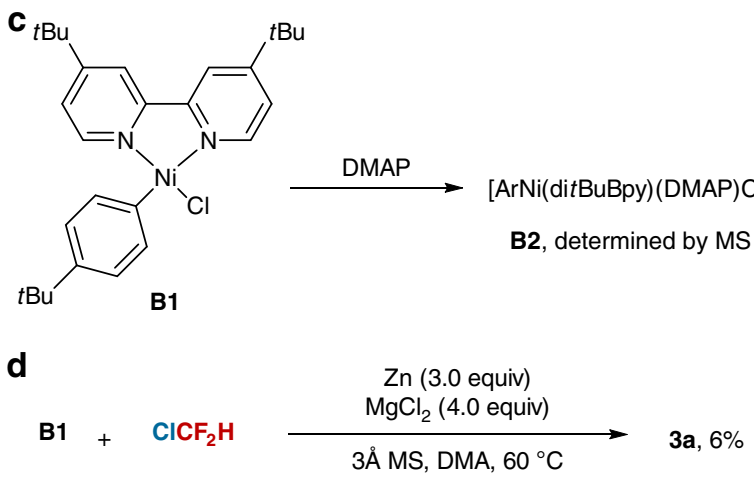

Fig. 5 The role of DMAP. a $\left[\mathrm{NiCl}_{2}(\mathrm{ditBuBpy})\right]$ (D1) catalyzed reaction between $\mathbf{2 a}$ and $\mathbf{1}$ with or without DMAP. b $\left[N \mathrm{NiCl}_{2}(\mathrm{DMAP})_{4}\right](\mathbf{D 2})$ catalyzed reaction between $\mathbf{2 a}$ and $\mathbf{1}$ with or without ditBuBpy. $\mathbf{c}$ Reaction of $\mathbf{B 1}$ with $\mathrm{CICF}_{2} \mathrm{H}$ in the presence of DMAP. d Reaction of $\mathbf{B} \mathbf{1}$ with $\mathrm{CICF}_{2} \mathrm{H}$ without DMAP

C

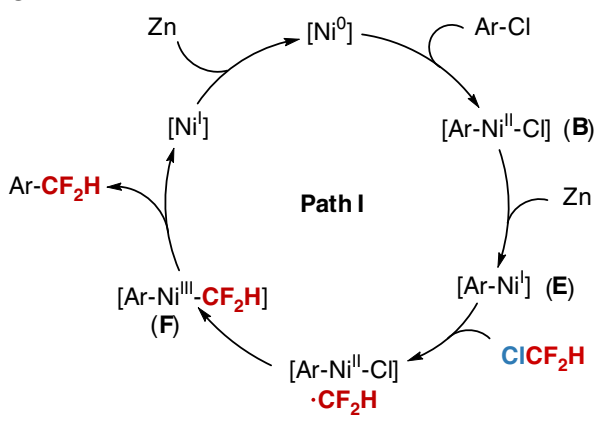

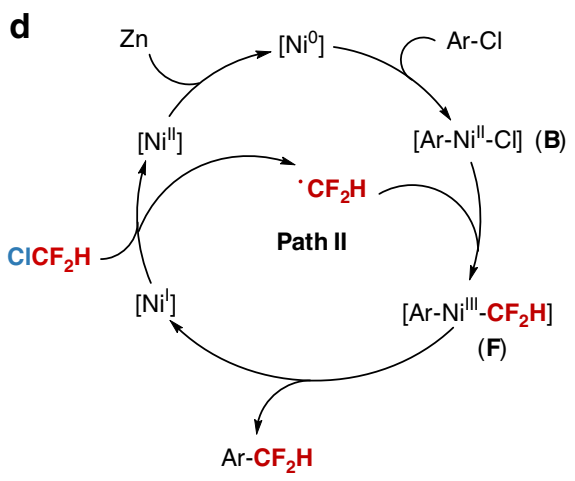

Fig. 6 Proposed reaction mechanism. a Proposed mechanism via a radical-cage-rebound process. b Proposed mechanism via a radical chain process

nickel species. However, the exact role of $\mathrm{MgCl}_{2}$ remains elusive. On the other hand, the omission of $\mathrm{Zn} / \mathrm{MgCl}_{2}$ could provide $\mathbf{3 a}$ in $12 \%$ yield (Fig. $4 \mathrm{a}$ ), suggesting that intermediate $\mathbf{B 1}$ reduction is not needed without $\mathrm{MgCl}_{2}$.

Thirdly, to probe whether a difluoromethyl radical existed in the reaction, several radical trapping experiments were conducted. Radical inhibition experiments showed that the reaction could be readily inhibited by addition of electron transfer scavenger 1,4-dinitrobenzene ${ }^{22}$ or a radical scavenger 2,2,6,6-tetramethyl-1-piperidinyloxy (TEMPO) (Supplementary Table 16). In addition, radical clock experiment showed that a ring-expanded product 9 was formed in $18 \%$ yield when $\mathrm{ClCF}_{2} \mathrm{H}$ was treated with $\alpha$-cyclopropylstyrene $\mathbf{8}$ in the presence of aryl chloride $\mathbf{2 c}$ under standard reaction conditions (Fig. 4e). However, when a radical scavenger TEMPO was added to the reaction, the reaction was totally inhibited without observation of compounds 9 and $\mathbf{3 c}$ (Supplementary Methods). Compound $\mathbf{9}$ could also be obtained by a stoichiometric reaction of nickel complex $\mathbf{B 1}$ with $\mathrm{ClCF}_{2} \mathrm{H}$ and 8 under standard reaction conditions (Fig. 4f). But difluoromethyl nickel complex $\mathbf{C l}$ failed to provide compound 9 (Fig. 4g), thus ruling out the possible formation of compound 9 from $\mathbf{C l}$ through the Ni-concerted insertion mechanism (Supplementary Fig. 142b). Furthermore, the possibility of formation of compound 9 from aryldifluoromethyl nickel complex Ar-[Ni]$\mathrm{CF}_{2} \mathrm{H}$ generated in situ between $\mathbf{B 1}$ and $\mathrm{ClCF}_{2} \mathrm{H}$ is also unlikely, as no ring-opening product $\mathbf{1 0}$ was observed by treatment of $\mathbf{B} \mathbf{1}$ with $\mathrm{ClCF}_{2} \mathrm{H}$ and 8 (Fig. $4 \mathrm{f}$ and Supplementary Fig. 142c). Therefore, these results suggest that the formation of 9 via a radical pathway (Supplementary Fig. 142a) is reasonable and a difluoromethyl radical species is involved in current catalytic cycle.

Finally, to establish the role of DMAP in the reaction, we prepared nickel complexes $\left[\mathrm{NiCl}_{2}(\mathrm{dit} B \mathrm{BuBpy})\right]$ (D1) and $\left[\mathrm{NiCl}_{2}(\mathrm{DMAP})_{4}\right](\mathbf{D} 2)^{27}$. Both of them could serve as precatalysts 
and provided 3a in comparable yields (Fig. 5a, b). However, D1 provided 3a in a lower yield (16\%) without DMAP (Fig. 5a) and no 3a was observed by using D2 in the absence of ditBuBpy (Fig. 5b). Additionally, a DMAP coordinated nickel complex B2 was observed by reaction of $\mathbf{B 1}$ with DMAP, which could also produce $\mathbf{3 a}$ in a $15 \%$ yield (Fig. 5 c). But only $6 \%$ yield of $\mathbf{3 a}$ was obtained without DMAP (Fig. $5 \mathrm{~d}$ ). These results demonstrate that DMAP can function as a co-ligand to coordinate to the nickel center and thus facilitate the catalytic cycle.

We also performed a Hammett-type analysis of the reaction (Supplementary Fig. 137 and 138). Plots of $\log \left(k_{\text {rel }}\right)$ versus $\sigma$ and $\sigma$ $(-)$ were linear with moderate quality $\left(R^{2} \sim 0.93\right)$, and the slope $(\rho)$ was between 1.9 and $2.0^{30,41,42}$. The $\rho$ values are smaller than those reports on stoichiometric studies of the oxidative addition of aryl halides to $\mathrm{Ni}(4.4-8.8)^{43,44}$, indicating that the oxidative addition of aryl chlorides to $\mathrm{Ni}(0)$ is not rate-determining step ${ }^{45}$. On the basis of these results and previous reports ${ }^{28,29}$, we propose that the reaction starts from aryl chloride via a radical-cagerebound process ${ }^{29}$ (Fig. 6a). An oxidative addition of aryl chloride to $\mathrm{Ni}(0)$ initiates the reaction. Subsequently, the resulting nickel(II) complex $\left[\mathrm{Ar}-\mathrm{Ni}^{\mathrm{II}}-\mathrm{Cl}\right](\mathbf{B})$ is reduced by $\mathrm{Zn}$ to generate $\left[\mathrm{Ar}-\mathrm{Ni}^{\mathrm{I}}\right](\mathbf{E})$. $\mathbf{E}$ undergoes the second oxidative addition with $\mathrm{ClCF}_{2} \mathrm{H}$ to produce $\left[\mathrm{Ar}-\mathrm{Ni}^{\mathrm{III}}-\mathrm{CF}_{2} \mathrm{H}\right](\mathbf{F})$ through a cage rebound process, in which a difluoromethyl radical . $\mathrm{CF}_{2} \mathrm{H}$ is produced via a single-electron-transfer pathway, subsequently, the resulting $\cdot \mathrm{CF}_{2} \mathrm{H}$ rapidly recombines with [Ar$\left.\mathrm{Ni}^{\mathrm{II}}-\mathrm{Cl}\right]$ to give $\mathbf{F}$. Finally, $\mathbf{F}$ undergoes reductive elimination to deliver difluoromethylated arenes and $\left[\mathrm{Ni}^{\mathrm{I}}\right] .\left[\mathrm{Ni}^{\mathrm{I}}\right]$ is further reduced by $\mathrm{Zn}$ to regenerate $\left[\mathrm{Ni}^{0}\right]$. Alternatively, a radical chain mechanism ${ }^{28,46}$ is also possible (Fig. 6b) as the intermediate B1 could also lead to difluoromethylated product without reduction by $\mathrm{Zn}$ (Fig. 4a). In this pathway, the $\cdot \mathrm{CF}_{2} \mathrm{H}$ generated by reaction of $\left[\mathrm{Ni}^{\mathrm{I}}\right]$ with $\mathrm{ClCF}_{2} \mathrm{H}$ diffuses to the solution to combine with $\left[\mathrm{Ar}-\mathrm{Ni}^{\mathrm{II}}-\mathrm{Cl}\right] \mathbf{B}$ to produce $\mathbf{F}$, which undergoes reductive elimination to give difluoromethylated product. Finally, the resulting $\left[\mathrm{Ni}^{\mathrm{II}}\right]$ is reduced by $\mathrm{Zn}$ to regenerate $\left[\mathrm{Ni}^{0}\right]$ (Supplementary Fig. 144).

In conclusion, we have developed a practical nickel-catalyzed difluoromethylation of (hetero)aryl chlorides and bromides with abundant and inexpensive $\mathrm{ClCF}_{2} \mathrm{H}$, representing a new strategy for fluoroalkylation reactions. The reaction proceeds under mild reaction conditions and can efficiently access a wide range of difluoromethylated (hetero)aromatics, including pharmaceuticals. Comparing to the previous difluoromethylation methods ${ }^{3-12,17}$, the current nickel-catalyzed process features several advantages, inexpensive $\mathrm{ClCF}_{2} \mathrm{H}$ and low-cost nickel catalyst; more accessible and cheaper aryl chlorides as well as no need for preformed arylmetals; broad substrate scope including a variety of heteroaromatics and pharmaceuticals; synthetic simplicity and convenience without prefunctionalization of drugs and biologically active molecules. Particularly, the ability of direct modulation of pharmaceuticals by using $\mathrm{ClCF}_{2} \mathrm{H}$ provides good opportunities to discover new medicinal agents. The additives $\mathrm{MgCl}_{2}$ and DMAP are critical to the reaction efficiency and DMAP can serve as a coligand to facilitate the catalytic cycle. Preliminary mechanistic studies reveal that the reaction starts from the oxidative addition of aryl halides to $\mathrm{Ni}(0)$ and a difluoromethyl radical is involved in the reaction, which is in contrast to the previous difluorocarbene pathway, thus paving a new way for applications of $\mathrm{ClCF}_{2} \mathrm{H}$ in organic synthesis and related chemistry.

\section{Methods}

General procedure for the nickel catalyzed cross-coupling. To a $25 \mathrm{~mL}$ of Schlenk tube were added aryl chloride $\mathbf{2}, \mathbf{4}$, or $\mathbf{6}\left(0.2 \mathrm{mmol}, 1.0\right.$ equiv.), $\mathrm{NiCl}_{2}(10$ mol\%), L4 (5 mol\%), zinc dust (3.0 equiv.), $\mathrm{MgCl}_{2}$ (4.0 equiv.), $3 \AA \mathrm{MS}(100 \mathrm{mg}$ ) and DMAP (20 mol\%). The mixture was evacuated and backfilled with argon for three times, DMA (2 mL) and $\mathrm{ClCF}_{2} \mathrm{H} 1$ (2.6 M in DMA, $1.3 \mathrm{mmol}$, 6.5 equiv.) were then added. The Schlenk tube was screw capped and put into a preheated oil bath $\left(60^{\circ} \mathrm{C}\right)$. After stirring for $20 \mathrm{~h}$, the reaction mixture was cooled to room temperature and diluted with ethyl acetate $(2 \mathrm{~mL})$. The yield was determined by ${ }^{19} \mathrm{~F}$ NMR using fluorobenzene as an internal standard before working up. Then the reaction mixture was filtered with a pad of cellite. The filtrate was washed with brine, extracted with EtOAc for three times. Then the organic layer was dried over $\mathrm{Na}_{2} \mathrm{SO}_{4}$ and concentrated. The residue was purified with silica gel chromatography to give product 3,5 , or 7 . Isolated yield is based on the average of two runs under identical conditions.

Data availability. The authors declare that all the data supporting the findings of this study are available within the paper and its supplementary information files. CCDC 1572871 contains the supplementary crystallographic data for $\mathbf{C 1}$. These data can be obtained free of charge from the Cambridge Crystallographic Data Centre via www.ccdc.cam.ac.uk/data_request/cif.

Received: 12 September 2017 Accepted: 19 February 2018 Published online: 21 March 2018

\section{References}

1. Hudlicky, M. \& Pavlath, A. E. Chemistry of Organic Fluorine Compounds II. (American Chemical Society, Washington, DC, 1995).

2. Wang, J. et al. Fluorine in pharmaceutical industry: fluorine-containing drugs introduced to the market in the last decade (2001-2011). Chem. Rev. 114, 2432-2506 (2014).

3. Fujikawa, K., Fujioka, Y., Kobayashi, A. \& Amii, H. A new method for aromatic difluoromethylation: copper-catalyzed cross-coupling and decarboxylation sequence from aryl iodides. Org. Lett. 13, 5560-5563 (2011).

4. Fier, P. S. \& Hartwig, J. F. Copper-mediated difluoromethylation of aryl and vinyl iodides. J. Am. Chem. Soc. 134, 5524-5527 (2012).

5. Prakash, G. K. et al. Copper-mediated difluoromethylation of (hetero)aryl iodides and beta-styryl halides with tributyl(difluoromethyl)stannane. Angew. Chem. Int. Ed. 51, 12090-12094 (2012).

6. Matheis, C., Jouvin, K. \& Goossen, L. J. Sandmeyer difluoromethylation of (hetero-)arenediazonium salts. Org. Lett. 16, 5984-5987 (2014).

7. Fujiwara, Y. et al. A new reagent for direct difluoromethylation. J. Am. Chem Soc. 134, 1494-1497 (2012).

8. Gu, Y., Leng, X. \& Shen, Q. Cooperative dual palladium/silver catalyst for direct difluoromethylation of aryl bromides and iodides. Nat. Commun. 5, 5405-5412 (2014).

9. Feng, Z., Min, Q. Q. \& Zhang, X. Access to difluoromethylated arenes by Pdcatalyzed reaction of arylboronic acids with bromodifluoroacetate. Org. Lett. 18, 44-47 (2016).

10. Xu, L. \& Vicic, D. A. Direct difluoromethylation of aryl halides via base metal catalysis at room temperature. J. Am. Chem. Soc. 138, 2536-2539 (2016).

11. Serizawa, H., Ishii, K., Aikawa, K. \& Mikami, K. Copper-catalyzed difluoromethylation of aryl iodides with (difluoromethyl)zinc reagent. Org. Lett. 18, 3686-3689 (2016).

12. Miao, W. et al. Iron-catalyzed difluoromethylation of arylzincs with difluoromethyl 2-pyridyl sulfone. J. Am. Chem. Soc. 140, 880-883 (2018).

13. Hine, J. \& Porter, J. J. Methylene derivatives as intermediates in polar reactions. VIII. Difluoromethylene in the reaction of chlorodifluoromethane with sodium methoxide. J. Am. Chem. Soc. 79, 5493-5496 (1957).

14. Miller, T. G. \& Thanassi, J. W. The preparation of aryl difluoromethyl ethers J. Org. Chem. 25, 2009-2012 (1960).

15. Moore, G. G. I. Fluoroalkanesulfonyl chlorides. J. Org. Chem. 44, 1708-1711 (1979).

16. Nawrot, E. \& Jonczyk, A. Difluoromethyltrialkylammonium salts--their expeditious synthesis from chlorodifluoromethane and tertiary amines in the presence of concentrated aqueous sodium hydroxide. The catalytic process. $J$. Org. Chem. 72, 10258-10260 (2007)

17. Feng, Z., Min, Q. Q., Fu, X. P., An, L. \& Zhang, X. Chlorodifluoromethanetriggered formation of difluoromethylated arenes catalysed by palladium. Nat. Chem. 9, 918-923 (2017).

18. Xiao, Y. L., Guo, W. H., He, G. Z., Pan, Q. \& Zhang, X. Nickel-catalyzed crosscoupling of functionalized difluoromethyl bromides and chlorides with aryl boronic acids: a general method for difluoroalkylated arenes. Angew. Chem. Int. Ed. 53, 9909-9913 (2014).

19. Gu, J. W., Min, Q. Q., Yu, L. C. \& Zhang, X. Tandem difluoroalkylationarylation of enamides catalyzed by nickel. Angew. Chem. Int. Ed. 55, 12270-12274 (2016).

20. Shi, S. L. \& Buchwald, S. L. Palladium-catalyzed intramolecular C-H difluoroalkylation: synthesis of substituted 3,3-difluoro-2-oxindoles. Angew. Chem. Int. Ed. 54, 1646-1650 (2015). 
21. Zhou, Q.-L. \& Huang, Y.-Z. Direct fluoroalkylation of aromatic compounds catalyzed by tetrakis(triphenylphosphine)nickel. J. Fluor. Chem. 43, 385-392 (1989).

22. Huang, X.-T. \& Chen, Q.-Y. Nickel(0)-catalyzed fluoroalkylation of alkenes, alkynes, and aromatics with perfluoroalkyl chlorides. J. Org. Chem. 66, 4651-4656 (2001).

23. Schwaebe, M. K., McCarthy, J. R. \& Whitten, J. P. Nickel(0)-catalyzed coupling of vinylzirconiums to $\alpha$-bromo- $\alpha$, $\alpha$-difluoro esters. Convenient generation of a functionalized allyldifluoro moiety. Tetrahedron Lett. 41, 791-794 (2000).

24. Liang, Y. \& Fu, G. C. Catalytic asymmetric synthesis of tertiary alkyl fluorides: Negishi cross-couplings of racemic alpha,alpha-dihaloketones. J. Am. Chem. Soc. 136, 5520-5524 (2014).

25. Liang, Y. \& Fu, G. C. Catalytic asymmetric synthesis of tertiary alkyl fluorides: Negishi cross-couplings of racemic alpha,alpha-dihaloketones. J. Am. Chem. Soc. 136, 5520-5524 (2014).

26. Jiang, X., Sakthivel, S., Kulbitski, K., Nisnevich, G. \& Gandelman, M. Efficient synthesis of secondary alkyl fluorides via Suzuki cross-coupling reaction of 1halo-1-fluoroalkanes. J. Am. Chem. Soc. 136, 9548-9551 (2014).

27. Xiao, Y. L., Min, Q. Q., Xu, C., Wang, R. W. \& Zhang, X. Nickel-catalyzed difluoroalkylation of (hetero)arylborons with unactivated 1-bromo-1,1difluoroalkanes. Angew. Chem. Int. Ed. 55, 5837-5841 (2016).

28. Weix, D. J. Methods and mechanisms for cross-electrophile coupling of $\left.\mathrm{Csp}^{2}\right)$ halides with alkyl electrophiles. Acc. Chem. Res. 48, 1767-1775 (2015).

29. Gu, J., Wang, X., Xue, W. \& Gong, H. Nickel-catalyzed reductive coupling of alkyl halides with other electrophiles: concept and mechanistic considerations. Org. Chem. Front. 2, 1411-1421 (2015).

30. Everson, D. A., Jones, B. A. \& Weix, D. J. Replacing conventional carbon nucleophiles with electrophiles: nickel-catalyzed reductive alkylation of aryl bromides and chlorides. J. Am. Chem. Soc. 134, 6146-6159 (2012).

31. Yin, H., Zhao, C., You, H., Lin, K. \& Gong, H. Mild ketone formation via Nicatalyzed reductive coupling of unactivated alkyl halides with acid anhydrides. Chem. Commun. 48, 7034-7036 (2012).

32. An, L., Xiao, Y. L., Min, Q. Q. \& Zhang, X. Facile access to fluoromethylated arenes by nickel-catalyzed cross-coupling between arylboronic acids and fluoromethyl bromide. Angew. Chem. Int. Ed. 54, 9079-9083 (2015).

33. Wang, X., Wang, S., Xue, W. \& Gong, H. Nickel-catalyzed reductive coupling of aryl bromides with tertiary alkyl halides. J. Am. Chem. Soc. 137, 11562-11565 (2015).

34. Meanwell, N. A. Synopsis of some recent tactical application of bioisosteres in drug design. J. Med. Chem. 54, 2529-2591 (2011).

35. Erickson, J. A. \& McLoughlin, J. I. Hydrogen bond donor properties of the difluoromethyl group. J. Org. Chem. 60, 1626-1631 (1995).

36. Burton, D. J. \& Hartgraves, G. A. The preparation of $\mathrm{HCF}_{2} \mathrm{CdX}$ and $\mathrm{HCF}_{2} \mathrm{ZnX}$ via direct insertion into the carbon halogen bond of $\mathrm{CF}_{2} \mathrm{HY}(\mathrm{Y}=\mathrm{Br}, \mathrm{I})$. J. Fluor. Chem. 128, 1198-1215 (2007).

37. Shields, B. J. \& Doyle, A. G. Direct $\mathrm{C}\left(\mathrm{s}^{\mathrm{p}} 3\right)-\mathrm{H}$ Cross coupling enabled by catalytic generation of chlorine radicals. J. Am. Chem. Soc. 138, 12719-12722 (2016).

38. Maleckis, A. \& Sanford, M. S. Synthesis of fluoroalkyl palladium and nickel complexes via decarbonylation of acylmetal species. Organometallics 33, 3831-3839 (2014).

39. Bour, J. R., Camasso, N. M. \& Sanford, M. S. Oxidation of Ni(II) to Ni(IV) with aryl electrophiles enables Ni-mediated aryl- $\mathrm{CF}_{3}$ coupling. J. Am. Chem. Soc. 137, 8034-8037 (2015).

40. Colon, I. \& Kelsey, D. R. Coupling of aryl chlorides by nickel and reducing metals. J. Org. Chem. 51, 2627-2637 (1986).

41. Cassar, L. \& Foà, M. Nickel-catalyzed carbonylation of aromatic halides at atmospheric pressure of carbon monoxide. J. Organomet. Chem. 51, 381-393 (1973).
42. Saito, S., Oh-tani, S. \& Miyaura, N. Synthesis of biaryls via a nickel(0)catalyzed cross-coupling reaction of chloroarenes with arylboronic acids. $J$. Org. Chem. 62, 8024-8030 (1997).

43. Foà, M. \& Cassar, L. Oxidative addition of aryl halides to tris (triphenylphosphine)nickel(0). J. Chem. Soc. Dalton Trans. 2572-2576 (1975).

44. Tsou, T. T. \& Kochi, J. K. Mechanism of oxidative addition. Reaction of nickel (0) complexes with aromatic halides. J. Am. Chem. Soc. 101, 6319-6332 (1979).

45. Weissman, H. \& Milstein, D. Highly active PdII cyclometallated imine catalyst for the Suzuki reaction. Chem. Commun. 1901-1902 (1999).

46. Ren, Q., Jiang, F. \& Gong, H. DFT study of the single electron transfer mechanisms in Ni-catalyzed reductive cross-coupling of aryl bromide and alkyl bromide. J. Organomet. Chem. 770, 130-135 (2014).

\section{Acknowledgements}

Financial support for this work was provided by the National Natural Science Foundation of China $(21425208,21672238,21421002$, and 21332010), the National Basic Research Program of China (973 Program) (No. 2015CB931900), the Strategic Priority Research Program of the Chinese Academy of Sciences (No. XDB20000000), and SIOC.

\section{Author contributions}

C.X. and W.-H.G. contributed equally to this work. X.Z., C.X., and W.-H.G. conceived and designed the experiments. C.X. and W.-H.G. performed the experiments. C.X. conducted all the mechanism studies. X.H. and X.-Y.Z. prepared some starting materials. Y.-L.G. conducted MS analysis of nickel complexes. C.X. and W.-H.G. analyzed the data. X.Z. wrote the paper. All authors discussed the results and commented on the manuscript.

\section{Additional information}

Supplementary Information accompanies this paper at https://doi.org/10.1038/s41467018-03532-1.

Competing interests: The authors declare no competing interests.

Reprints and permission information is available online at http://npg.nature.com/ reprintsandpermissions/

Publisher's note: Springer Nature remains neutral with regard to jurisdictional claims in published maps and institutional affiliations.

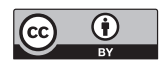

Open Access This article is licensed under a Creative Commons Attribution 4.0 International License, which permits use, sharing, adaptation, distribution and reproduction in any medium or format, as long as you give appropriate credit to the original author(s) and the source, provide a link to the Creative Commons license, and indicate if changes were made. The images or other third party material in this article are included in the article's Creative Commons license, unless indicated otherwise in a credit line to the material. If material is not included in the article's Creative Commons license and your intended use is not permitted by statutory regulation or exceeds the permitted use, you will need to obtain permission directly from the copyright holder. To view a copy of this license, visit http://creativecommons.org/ licenses/by/4.0/.

(C) The Author(s) 2018 